Original article

\title{
Relationships at work and psychosocial risk: The feeling of belonging as indicator and mediator
}

\section{Relations au travail et risque psychosocial : le sentiment d'appartenance comme indicateur et médiateur}

\author{
F. Coissard ${ }^{a}$, M.-L. Ndao ${ }^{\mathrm{a}}$, D. Gilibert ${ }^{\mathrm{b}, *}$, I. Banovic $^{\mathrm{c}}$ \\ a Université de Lorraine, INTERSPY EA 4432, 3, place Godefroy-de-Bouillon, BP. 3397, 54015 Nancy cedex, France \\ ${ }^{\mathrm{b}}$ Université Paul-Valéry Montpellier 3, université Montpellier, EPSYLON EA 4556, 34000 Montpellier, France \\ c Université de Rouen Normandie, CRFDP EA 7475, 76821 Mont-Saint-Agnan cedex, France
}

\section{A R T I C L E I N F O}

\section{Article history:}

Received 24 September 2015

Received in revised form 11 October 2017

Accepted 11 October 2017

\section{Keywords:}

Feeling of belonging

Identification with the team

Tension

Burnout

Prevention of psychosocial risk

\begin{abstract}
A B S T R A C T
Introduction/objective. - This article highlights the links between, one the one hand, the feeling of belonging to the work group and, on the other hand, the tension and burnout experienced, amongst 444 employees in a hospital centre.

Methodology. - The methodology is based on the use of 4 self-administered questionnaires (Karase k's JCQ Maslach's MBI, Quality of relationships with parties concerned and Feeling of belonging) and is based on correlations and multiple regressions.

Results. - The results highlight the fact that relationships perceived as generally relaxed with the different people concerned (care team, doctors, management and administrative staff), predicted Karase k's three dimensions and those assessed by the Maslach Burnout Inventory (MBI). Similarly, the feeling of belonging predicted all these variables. Most of the time it played a mediating role between the perceived quality of relationships and the different measures of well-being at work. So, the feeling of belonging seems to be a variable of interest, which can play a key role in the prevention of suffering at work.
\end{abstract}

(c) 2017 Elsevier Masson SAS. All rights reserved.

\section{R É S U M É}

Introduction/objectif. - Cet article met en évidence des liens entre, d'une part, le sentiment appartenance au collectif de travail et, d'autre part, la tension et l'épuisement professionnels ressentis, auprès de 444 agents d'un centre hospitalier.

Méthodologie. - La méthodologie est basée sur l'utilisation de 4 questionnaires auto-administrés (JCQ de Karase $\mathrm{k}$, MBI de Maslach, Qualité des relations avec les parties prenantes et Sentiment d'appartenance) et se fonde sur des corrélations et régressions multiples.

Résultats. - Les résultats mettent en évidence que des relations perçues comme globalement détendues avec les différentes parties prenantes (équipe soignante, médecins, encadrement et administration), prédisent les trois dimensions du Karase $k$ ainsi que sur celles évalués par le Maslach Burnout Inventory (MBI). De la même façon, le sentiment d'appartenance prédit l'ensemble de ces variables. Il joue la plupart du temps un rôle médiateur entre la qualité perçue des relations et les différentes mesures de bien-être au travail. Le sentiment d'appartenance semble donc bien être une variable d'intérêt, pouvant jouer un rôle clé dans la prévention de la souffrance au travail.

C 2017 Elsevier Masson SAS. Tous droits réservés.

\footnotetext{
* Corresponding author.

E-mail address: Daniel.Gilibert@univ-montp3.fr (D. Gilibert).
} 


\section{Introduction}

Since the introduction of the "2007-2012 hospital plan" reforms, French hospitals have undergone profound changes, the consequences of which have been an increase in malaise and suffering experienced at work (Gilibert \& Daloz, 2008; Roland-Lévy, Lemoine, \& Jeoffrion, 2014). In fact, the methods of funding hospitals and in the way they operate have changed very rapidly, in order to meet government requirements for cost reduction, while retaining their initial objectives to provide care and public service. Like private companies, hospitals today must cope with the problems of efficiency and profitability, which creates a paradox for the healthcare profession: in the beginning, hospitals were a place of charity and then of not-for-profit care. To this can be added the complexity of managing the production systems of "hypermodern", neo-bureaucratic organisations (Lamrani, 2014) which could perhaps be the cause of an environment experienced as harmful, and conducive to the emergence of psychosocial risks. In this management context of promoting individualisation at work, it is interesting to re-examine the collective dimension of work in depth (Clot, 2008).

This study was conducted in a hospital centre as part of an assessment of the well-being of its employees, after the reorganisation of work teams $(3 \times 12$ h days weekly instead of $5 \times 7 \mathrm{~h} 45 \mathrm{~min}$ days). Beyond these reorganisations, without any notable effects on quality of life, our aim was to examine identification with the institution and the feeling of belonging to this group, as a factor influencing the professional tension experienced in the face of work content and in a state of burnout. After a reminder of the literature related to these different concepts and their connections, we will present the concept of identification underlying the feeling of belonging to the work group. We will see how this variable can be viewed as being central in the measurement and management of psychosocial risks.

\section{Theoretical section}

\subsection{The feeling of belonging and identification with the team}

The feeling of belonging, studied for a long time in the field of psychology, seems to be an interesting area for exploration, even though few studies on psychosocial risks have focused on it. Belonging to a group is thought to be more than a simple feeling, it is a necessity, a fundamental need to belong. Levett-Jones and Lathlean (2008) and Wiesenfeld (1996), define it as a fundamental need to belong, to feel accepted and to define oneself in relation to others and in relationships with them. A feeling of isolation at work (real or perceived) is thought to be harmful for individuals. On this subject, Chevrier (2012) points to a gradual dilution of the feeling of belonging, through geographical remoteness and confinement in an activity, whereas the fact of being integrated in a work group promotes closeness and therefore social connections, both formal and informal. The expression of a feeling of belonging illustrates the fact that an individual considers themselves to be part of a group, with a level of attachment of the employee to the team of which they are part, and to the organisation which employs them (Gueudar-Delahaye, 2012; Porter, Steers, Mowday, \& Boulian, 1974). This is a process through which individuals are inter-connected and define themselves in relation to each other, in accordance with their interests and affinities. Belonging structurally to a team therefore gives people a status in it, allows them to explore possible methods of cooperation, to seek complementary relationships with other members and finally to offer specialised contributions (Dameron, 2004). According to the same author, it is in interaction that everyone's role is defined, and their place in relation to the other members. This feeling of belonging is closely linked to identification with the group (Gueudar-Delahaye, 2012). It seems difficult to study this feeling of belonging without drawing on the concept of identification with the group, traditionally studied in intergroup processes (Ashforth, Harrison, \& Corley, 2008; Chedotel, 2004). In fact, Turner has already referred to the fact that the identification of an individual with a social group prompts the emergence of a feeling of belonging, which can go as far as the feeling of being at one with the membership group, during intergroup comparisons (Buton, Fontenay, \& Heuzé, 2006; Pansu, Tarquinio, \& Gilibert, 2005). Therefore, identification is thought to lead to a feeling of belonging, to unity of meaning and feeling at one with others. It is thought to allow the individual to see themselves as a member of a group which supplies norms, values and points of reference. Identification therefore refers to a process through which an individual considers themselves as connected to other individuals or to a team (Cooper \& Thatcher, 2010). Identifying with a team means feeling that this group is one's own, perceiving oneself as a part of it, and considering its actions as one's own, just like its successes and failures.

\subsection{The feeling of belonging to the work group as a contributor to well-being}

Our general premise is that the feeling of belonging and identification with the team can influence the tension at work and burnout experienced. In fact, when members feel integrated and identify with the team, they are thought to perceive, not only greater social support, but also greater autonomy in the performance of their tasks or even a lower psychological demand faced with their tasks (Laugaa, Rascle, \& Bruchon-Schweitzer, 2008). At a more subjective level, the emotional burnout experienced is likely to be lower, as is the depersonalisation of relationships with patients and lack of self-fulfilment in work.

Chedotel (2004) suggests that identification and cooperation have an ambivalent relationship. Nevertheless, according to him, the level of identification can influence practices, and, in the case where this is high, leads to the construction of a cooperative environment in which each member will tend to perceive themselves as an entity in their own right within the group. Conversely, a low identification with the group will be conducive to inward-looking behaviours, both on the part of team members and of management (Conjard \& Jounourd, 2013). When members identify with the work team and perceive an interdependence between them, it is likely that this leads to the initiation, maintenance and strengthening of cooperation and coordination. Some people emphasise the fact that individualisation of performance and pay influences human relationships, whether within a team and/or in relationships with managerial staff, and induces objective isolation amongst employees, in turn reducing opportunities for exchange and cooperation (Lachmann, Larose, \& Pennicaud, 2010). Studying the feeling of belonging and identification with the work group, in connection with the quality of life at work, therefore appears essential.

\subsection{Tension at work and burnout}

In order to assess the perception which employees have of their work and the professional tension experienced, we used Karasek's three-dimensional model (1979), which has been widely documented. This model, two-dimensional initially, firstly examined decisional latitude (autonomy in the way of organising one's work) and psychological demand, which refers to workload and the disruptions which occur in this work. The study of social support was added to these two dimensions. This model is one of the most used in the study of psychosocial risks as it identifies impaired work situations, and the isolation which the employee can feel when 
faced with them (Marc, Grosjean, \& Marsella, 2011). All things being equal, the absence of social support and isolation at work appear to be factors in the deterioration of health. This latter dimension of social support includes support from colleagues and superiors, and a recognition of the importance of work carried out (Cerclé, Gadea, Hartmann, \& Lourel, 2008; Guilbert, Carrein, Guenole, \& Priolo, in press; Halbesleben, 2006). It thus refers to the possibility of an individual benefiting, or not benefiting, from technical support, from the understanding of their superiors, and from help and solidarity from their colleagues. As the new forms of work structures are suspected of promoting isolation of employees and thus a deterioration in work conditions, it appears to us important to explore the perception of work conditions via a Job content questionnaire (JCQ) and to verify the existence of a connection with the feeling of belonging and identification with team and more generally with the organisation.

Many studies have highlighted the connection between work conditions described as impaired, in accordance with Karasek's model, and the state of burnout experienced (Bakker, Demerouti, \& Euwema, 2005; Vandenberghe, Stordeur, \& d'Hoore, 2009). The phenomena of stress and subsequent burnout were described very early on (Bradley, 1969; Freudenberger, 1974; Maslach and Jackson, 1981). The model constructed by Maslach (1976) is the most used for assessing the level of employee burnout. It uses three dimensions of measurement which express a state of burnout: emotional burnout, which relates to the feeling of being emptied of all emotional resources, depersonalisation or withdrawal from relationships, which refers to the development of negative attitudes to users, and finally, lack of self-fulfilment at work, which reflects increasing doubts about one's professional abilities. Here, the syndrome is thought to arise from an interaction between the individual and an impaired work environment, in the face of which they burn out. The impairment factors developed by Maslach are work overload, lack of control, lack of reward, deterioration in group spirit, lack of fairness and conflict of interest.

According to Chatot-Henry, Chatot-Henry, and Courcier (2014) when a work situation is impaired, identification with the team, a feeling of belonging, and social support help staff to feel fulfilled and are thought to be linked to better perceived health. Moreover, a meta-analysis (Halbesleben, 2006) has demonstrated that social support has a beneficial impact on the three dimensions of burnout. The links between these models are well established, but on the other hand, few studies have measured the impact of the feeling of belonging on psychological well-being at work. We therefore hypothesise that a strong feeling of belonging and identification with the team will have a beneficial effect on each dimension of the two models used in this study (JCQ and MBI).

This hypothesis is also supported by the results of a recent study in a hospital environment (Roland-Lévy et al., 2014). It was observed, in particular, that demands linked to work and the emotional demands of relationships with patients are major causes for the suffering of hospital staff. In particular, the authors observe that the first thing which the healthcare professionals mention by common accord in relation to well-being at work concerns good relationships with colleagues and superiors. Other terms appear less frequently but are clearly linked: ("support", "respect", "being listened to", and having good "communication"), thus highlighting the role of the professional group as a potential contributor to well-being. Similarly, when they have to mention situations, which are problematic for them, and possible improvements, healthcare professionals firstly mention relationships within the team, followed by relationships with superiors, even before relationships with patients and workload. Beyond the nature of the care work itself, human relationships within teams and the hospital seem to be a key element in the psychosocial risk experienced. Other studies, carried out in the education sector, have also concluded that the feeling of belonging to an institution is negatively linked to emotional burnout and the intention to resign (Skaalvik \& Skaalvik, 2011a, 2011b). According to these authors, the feeling of belonging plays a protective role in the shift from the state of burnout to the intention to resign.

Although it may appear obvious that the perceived quality of relationships within the institution can be a good predictor of quality of life at work, we propose to verify that the feeling of belonging will also be an appropriate predictor of the three dimensions of Karasek's model and of Maslach's model. Moreover, and in a more exploratory fashion, we also expect this feeling of belonging to mediate the link existing between the quality of the relationships described and these measures of quality of life, thus suggesting that good relationships determine a good quality of life, insofar as they promote a feeling of belonging to the group (Fig. 1).

\section{Methodology}

\subsection{Context of the study}

The hospital centre in which this study was carried out is a hospital with 580 beds and around 1500 staff, including all socioprofessional categories. The request initially formulated concerned avenues of research to improve the well-being of the staff. Amongst the various avenues mentioned, one concerned caregivers' isolation and feeling of belonging (to the team, to the department and to the hospital) as being an important element in quality of life.

\subsection{Sample}

This study is based on the collection of 444 questionnaires from all the hospital's socio-professional categories, on a voluntary basis and with guaranteed anonymity (359 care staff, 78 technical and administrative staff and 7 people who did not supply this information). Table 1 below gives the detailed characteristics of the sample in accordance with gender, post occupied and mean age.

\subsection{Reminder of hypotheses}

We firstly expect to observe correlational links between the perceived quality of relationships, the feeling of belonging and positive results in terms of quality of life (and this across the three dimensions of Karasek's Job Content Questionnaire and the three dimensions of the Maslach Burnout Inventory, used as indicators

Table 1

Characteristics of the 444 respondents.

\begin{tabular}{ll}
\hline & Numbers $\%$ of the sample \\
\hline Gender & \\
Men & $43(9.7 \%)$ \\
Women & $397(89.4 \%)$ \\
Information not given & $4(0.9 \%)$ \\
Profession & \\
State registered nurse & $176(39.64 \%)$ \\
Nursing auxiliary - paediatric auxiliary & $125(28.15 \%)$ \\
Hospital service employee & $33(7.43 \%)$ \\
Medical-administrative assistant & $22(4.95 \%)$ \\
Technical-medical staff & $22(4.95 \%)$ \\
Midwife & $25(5.63 \%)$ \\
Hospital porter & $5(1.13 \%)$ \\
Healthcare executive & $20(4.5 \%)$ \\
Call handler & $4(0.9 \%)$ \\
Dietician & $1(0.23 \%)$ \\
Physiotherapist & $2(0.45 \%)$ \\
Paramedic & $1(0.23 \%)$ \\
Biologist & $1(0.23 \%)$ \\
Information not given & $7(1.58 \%)$ \\
Age & $\mathrm{M}=37.8$ years $\sigma=17.02$ \\
\hline
\end{tabular}




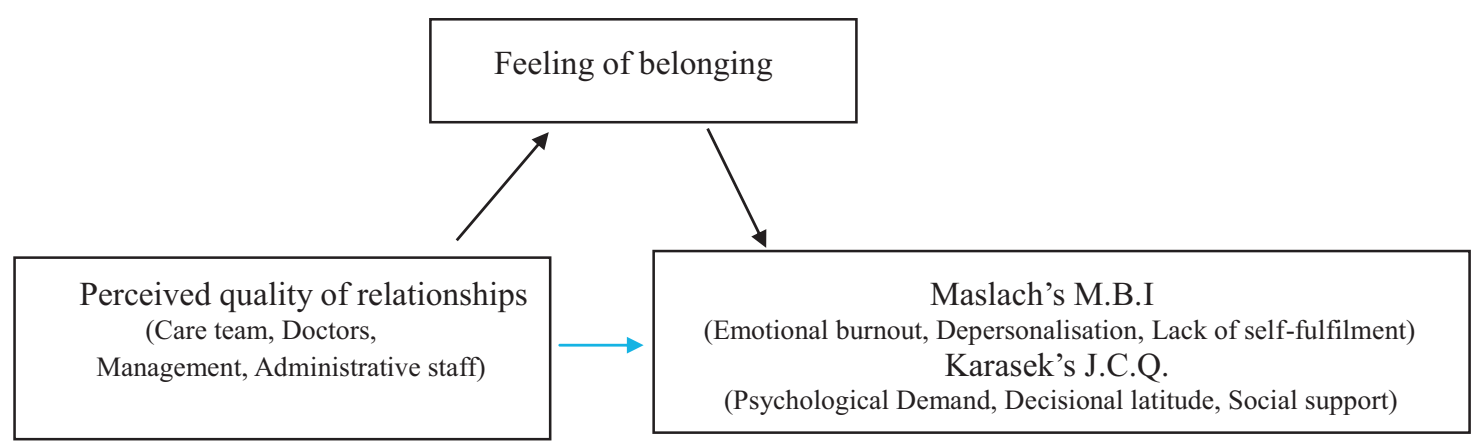

Fig. 1. Expected mediating role of the feeling of belonging, in predicting the 3 dimensions of the MBI and the JCQ by the perceived quality of relationships.

of well-being). The employees describing relationships as good and those feeling a high level of belonging, would perceive the psychological demand linked to work as lower, and would describe their decisional latitude at work and the social support received (JCQ) more positively. In a similar vein, the stronger their feeling of belonging, the lower would be their emotional burnout, the depersonalisation experienced in relationships with patients and the feeling of lack of self-fulfilment at work.

More generally speaking, it is a question of demonstrating that the feeling of belonging is a variable of interest in measuring quality of life at work, in which case we can also expect this measure to be statistically explanatory and central, in predicting the other measures of quality of life at work used during multiple regressions.

Not only would it be one of the variables which best assesses the level of the others, but, what is more, it could indicate the links observed between them. It would act particularly as a mediating variable between, on the one hand, the quality of human relationships experienced and, on the other hand, the level of burnout or the perception of work content as impaired.

\subsection{Tools and procedure}

The questionnaires used consisted of 4 self-administered scales allowing links to be established between the different concepts previously mentioned.

The use of Karasek's Job Content Questionnaire (Karaseck, 1979) in 26 items allowed us to assess psychological demand in 9 items with an alpha of 0.84 , social support in 8 items with a coefficient of 0.69 and decisional latitude in 9 items with an alpha of 0.67 .

The Maslach Burnout Inventory in 22 items was also used. This questionnaire assesses emotional burnout in 9 items and presents a Cronbach's alpha of 0.90 , depersonalisation in 5 items with a Cronbach's alpha of 0.79 and finally personal fulfilment in 8 items with a Cronbach's alpha of 0.71 .

A series of 4 items assessed relationship quality (from very tense to very relaxed on a scale of 1 to 10 ) with the other members of the care team, with the medical team of which the doctors were part, with first-line management and with the hospital's administrative staff. This scale presented a Cronbach's alpha of 0.78 , which allowed us, after specific analyses based on each item, to retain a single score for perceived quality of relationships. The factor analysis confirmed the existence of a single factor on which all the items have a factor loading higher than 0.70 .

In order to measure the feeling of belonging, a 9-item questionnaire was created. For each statement, the respondent had to rank their opinion between 1 : "totally disagree" to 10 "totally agree". The statements referred both to the feeling of belonging and the identification with groups which make up the work structure (I have a real feeling of belonging to the department I work in/I consider myself to be a member of the department I work in/I consider myself as fully part of the department I work in/The department
I work in is particularly motivating for me/I am happy to work in the department I work in/I consider that my department is one of the best departments in the hospital/I am very attached to the team of people who I work with regularly/I am very attached to the department as a whole/I am very attached to the hospital in general). A factor analysis without rotation produced a single factor on which virtually all the items contributed to a loading equivalent to 0.70 , (with the exception of the 9 th item which only contributed to 0.50). This scale also presented a Cronbach's alpha of 0.91 , which permitted us to retain only one single score for belonging.

\subsection{Statistical procedure}

As a first step, a correlation matrix was calculated to test the existence of correlational links between, on the one hand, the quality of relationships and the feeling of belonging and, on the other hand, the different dimensions of the MBI and those of Karasek. The strength of the links between these variables was then tested by multiple regressions, pitting the different significant predictors of the same predicted variable against each other, so as to produce the most directly explanatory predictor, independently of possible conceptual overlaps between the different predictors. This allowed us to determine when the feeling of belonging could be a central factor in the prediction of other measures. Finally, mediation analyses were carried out to check whether the feeling of belonging could also have the status of latent mediating variable and thus account for the existing links between the perceived quality of relationships in the hospital and the different measures of quality of life. For this the Sobel test was performed in order to make certain of the significance of the mediating role of the feeling of belonging.

It should be remembered that the aim of this article is, on the one hand, to demonstrate that the perceived quality of relationships and the feeling of belonging contribute to the quality of life at work and, on the other hand, that the feeling of belonging can reflect good relationships and thus mediate their effects on the quality of life of care staff.

\section{Results}

\subsection{Study of correlations}

A correlation matrix was calculated in order to reveal existing links between, on the one hand, the perceived quality of relationships, and the feeling of belonging and, on the other hand, the dimensions of Karasek and those of the MBI (Table 2).

The correlation analysis allowed us first of all to observe that the dimensions of the JCQ and the MBI were inter-correlated in 13 cases out of 15, (except the psychological demand of work which was unrelated to decisional latitude $r=+0.05$, ns. and self-fulfilment at work, $r=-0.01$, ns.). In addition, these 6 dimensions of quality of life are be predicted both by the quality of the different relationships 
Table 2

Means and standard deviations of the different measures and Bravais-Pearson correlation indices.

\begin{tabular}{|c|c|c|c|c|c|c|c|c|c|c|c|c|c|}
\hline & \multirow[t]{2}{*}{$\mathrm{m}$} & \multirow[t]{2}{*}{$\Sigma$} & \multicolumn{11}{|c|}{ Correlations } \\
\hline & & & 1. & 2. & 3. & 4. & 5. & 6. & 7. & 8. & 9. & 10. & 11. \\
\hline 1. Psych. demand & 25.80 & $(4.50)$ & 1.00 & & & & & & & & & & \\
\hline 2. Latitude & 67.96 & (9.39) & 0.05 & 1.00 & & & & & & & & & \\
\hline 3. Social support & 23.18 & (3.94) & $-0.18^{* *}$ & $0.37^{* *}$ & 1.00 & & & & & & & & \\
\hline 4. Burnout & 18.33 & $(11.0)$ & $0.44^{*}$ & $-0.25^{* *}$ & $-0.36^{* *}$ & 1.00 & & & & & & & \\
\hline 5. Depersonalisation & 5.53 & $(5.24)$ & $0.29^{* *}$ & $-0.19^{* *}$ & $-0.19^{* *}$ & $0.46^{*}$ & 1.00 & & & & & & \\
\hline 6. Fulfilment & 37.25 & (7.46) & $-0.01 \mathrm{~ns}$ & $0.33^{* *}$ & $0.29^{* *}$ & $-0.25^{* *}$ & $-0.21^{* *}$ & 1.00 & & & & & \\
\hline 7. Rel. with care staff & 7.88 & $(1.77)$ & $-0.18^{* *}$ & $0.18^{* *}$ & $0.42^{* *}$ & $-0.39^{* *}$ & $-0.18^{* *}$ & $0.24^{* *}$ & 1.00 & & & & \\
\hline 8. Rel. with doctors & 6.94 & $(2.04)$ & $0.26^{* *}$ & $0.25^{* *}$ & $0.33^{* *}$ & $-0.33^{* *}$ & $-0.23^{* *}$ & $0.24^{* *}$ & $0.52^{*}$ & 1.00 & & & \\
\hline 9. Rel. with management & 7.00 & $(2.34)$ & $-0.31^{* *}$ & $0.30^{* *}$ & $0.58^{*}$ & $-0.42^{*}$ & $-0.28^{* *}$ & $0.27^{* *}$ & $0.48^{*}$ & $0.51^{*}$ & 1.00 & & \\
\hline 10. Rel with admin. & 6.55 & $(2.11)$ & $-0.25^{* *}$ & $0.19^{* *}$ & $0.34^{* *}$ & $-0.31^{* *}$ & $-0.21^{* *}$ & $0.26^{* *}$ & $0.33^{* *}$ & $0.46^{*}$ & $0.50^{*}$ & 1.00 & \\
\hline 11. Belonging & 7.51 & (1.59) & $-0.18^{* *}$ & $0.35^{* *}$ & $0.55^{*}$ & $-0.44^{*}$ & $-0.26^{* *}$ & $0.40^{* *}$ & $0.60^{*}$ & $0.51^{*}$ & $0.55^{*}$ & $0.35^{* *}$ & 1.00 \\
\hline
\end{tabular}

Table 3

Summary of $\mathrm{R}^{2}$, B, $t$ and ranks, during 10 multiple regression analyses implying the feeling of belonging as predictor, in competition with all the other variables correlated.

\begin{tabular}{lllll}
\hline \multirow{2}{*}{ Predicted variables } & Adjusted $\mathrm{R}^{2}$ & \multicolumn{3}{l}{ Predictor: feeling of belonging } \\
\cline { 3 - 5 } & & Beta & $t$ & Rank \\
\hline Personal fulfilment & 0.19 & $0.26^{* *}$ & 5.19 & 1 \\
Rel. with care staff & 0.44 & $0.37^{* *}$ & 7.54 & 1 \\
Decisional latitude & 0.19 & $0.18^{* *}$ & 3.16 & 1 \\
Social support & 0.42 & $0.32^{* *}$ & 6.82 & 2 \\
Emotional burnout & 0.43 & $-0.17^{* *}$ & -3.45 & 2 \\
Rel. with doctors & 0.41 & $0.20^{* *}$ & 3.82 & 3 \\
Rel. with management & 0.51 & $0.13^{*}$ & 2.57 & 4 \\
Depersonalisation & 0.19 & $\mathrm{~ns}$ & & - \\
Psychological demands & 0.26 & $\mathrm{~ns}$ & & - \\
Rel. with admin. staff & 0.32 & $\mathrm{~ns}$ & & - \\
\hline${ }^{*} p<0.01$. & & & & \\
${ }^{* *} p<0.001$. & & & &
\end{tabular}

with the different interlocutors in the hospital, and by the feeling of belonging to the work group.

Finally, the feeling of belonging seemed to be easily predicted by the perceived quality of relationships with the care team $(r=+0.60, p<0.001)$, with the doctors $(r=+0.51, p<0.01)$, with the management $(r=+0.55, p<0.01)$, and with the administrative staff $(r=+0.35, p<0.001)$.

\subsection{Multiple regressions}

As the feeling of belonging was correlated and thus covered numerous other variables, it appeared to us essential to check its central role, through multiple regressions. The main results of the different multiple regression analyses are summarised in Table 3.

The results, presented here in ascending order, highlight the fact that the feeling of belonging was a sound and specific explanatory factor for seven of the ten predicted variables. The feeling of belonging was the variable which most directly explained personal fulfilment $(\beta=0.26, p<0.001)$, the relationship with care staff $(\beta=0.37, p<0.001)$ and decisional latitude $(\beta=0.18, p<0.001)$. This indicates that the stronger is the feeling of belonging, the better is the fulfilment of individuals in their work, the better are perceived relationships with colleagues in the care team and the higher is the autonomy experienced in the management of work. The feeling of belonging explains, in the second rank, perceived social support and emotional burnout $(\beta=0.32, p<0.001$ and $\beta=-0.17, p<0.001)$.

Regarding the relationship with the medical team and doctors $(\beta=0.20, p<0.001)$ and the relationship with management ( $\beta=0.13, p<0.01)$, the feeling of belonging remained specifically predictive, albeit in a less preferential fashion ${ }^{1}$. This did not however specifically predict depersonalisation, psychological demand or the quality of relationships with the administrative staff. ${ }^{2}$

These multiple regressions support our hypothesis overall, according to which the feeling of belonging can be a specific, directly explanatory measure for the other variables, considered one by one. Therefore, when the feeling of belonging is strong, it predicts, in a fairly direct and specific way, better self-fulfilment at work, a better climate with members of the care team, social support perceived as high, satisfactory decisional latitude and lower emotional burnout. In a less direct fashion, as other directly explanatory variables come into play, the feeling of belonging specifically predicts the perceived relationship with doctors and management. On the other hand, it does not specifically predict the depersonalisation of relationships with patients, psychological demand at work or the relationship with the administrative staff, which are most directly predicted by measures similar to these. Considered together, these analyses suggest that the measure of the feeling of belonging is actually a specific construct and, on the whole, fairly central amongst the others measured during our study.

\subsection{Mediation analysis: Sobel test}

In order to verify that the feeling of belonging could have the status of mediating variable between the perceived quality of relationships and the measures of quality of life, mediation analyses were performed.

\subsubsection{Mediating role of the feeling of belonging between the} perception of the quality of relationships with the other members of the team and the different dimensions of the MBI and the JCQ

A first series of mediation analyses, summarised in Table 4, allowed us to observe that the feeling of belonging was a mediator for the majority of the total, or else partial time, for the link between the quality of relationships with the care team and the

\footnotetext{
1 Nota Bene: social support and the relationship with the management have a particularly strong relationship, and predicted each other primarily. Burnout was explained primarily by psychological demand. The relationship with doctors was further explained by the relationship with the members of the care team and then by the relationship with the administrative staff. The relationship with management was primarily explained by social support and then by relationships with the administrative staff and doctors.

2 Depersonalisation was primarily explained by emotional burnout and selffulfilment. Psychological demand was explained by burnout, latitude and then by the relationship with the management. Finally, the relationship with the administrative staff was primarily explained by relationships with the management and doctors and by self-fulfilment at work.
} 
Table 4

Summary of Sobel tests evaluating the feeling of belonging as a mediator between the quality of relationships with the care team and the dimensions of the MBI and the JCQ. ${ }^{a}$

\begin{tabular}{lllll}
\hline Predicted variables of quality of life & B & ETB & Z & Mediation \\
\hline MBI - Emotional burnout & -2.36 & 0.37 & $-5.95^{* * *}$ & Partial \\
MBI - Depersonalisation & -0.76 & 0.20 & $-3.79^{* * *}$ & Total \\
MBI - Personal fulfilment & 1.73 & 0.26 & $6.08^{* * *}$ & Total \\
JCQ - Psychological demand & -0.41 & 0.16 & $-2.53^{*}$ & Total \\
JCQ - Decisional latitude & 2.32 & 0.35 & $5.86^{* * *}$ & Total \\
JCQ - Social support & 1.18 & 0.12 & $8.11^{* * *}$ & Partials \\
\hline
\end{tabular}

** $p<0.01$.

a Coefficient of 0.54 and standard deviations 0.04 .

${ }^{*} p<0.05$.

${ }^{* * *} p<0.001$.

\section{Table 5}

Summary of Sobel tests evaluating the feeling of belonging as a mediator between the perceived quality of relationships with doctors and the dimensions of the MBI and the JCQ. ${ }^{\mathrm{a}}$

\begin{tabular}{lllll}
\hline Predicted variables of quality of life & B & ETB & Z & Mediation \\
\hline MBI - Emotional burnout & -2.65 & 0.35 & $-6.49^{* * *}$ & Partial \\
MBI - Depersonalisation & -0.60 & 0.18 & $-3.20^{* *}$ & Partial \\
MBI - Personal fulfilment & 1.68 & 0.24 & $6.05^{* * *}$ & Total \\
JCQ - Psychological demand & -0.26 & 0.15 & -1.75 & ns \\
JCQ - Decisional latitude & 1.81 & 0.33 & $5.06^{* * *}$ & Total \\
JCQ - Social support & 1.26 & 0.12 & $8.14^{* * *}$ & Partial \\
\hline
\end{tabular}

${ }^{*} p<0.05$.

a Coefficient of 0.42 and standard deviation 0.04 .

** $p<0.01$.

*** $p<0.001$.

measures of quality of life (the 3 dimensions of the MBI and the JCQ being initially predicted by the quality of relationships with the care team).

\subsubsection{Mediating role of the feeling of belonging between the} perception of the quality of relationships with doctors and the different dimensions of the MBI and the JCQ

Concerning the quality of relationships with the medical team and doctors, which is a predictor of quality of life, the feeling of belonging also proved to be a satisfactory mediator. This was observed for the 3 dimensions of the MBI: with regard to self-fulfilment at work (Sobel $=6.05, p<0.001$, total mediation.) depersonalisation and emotional burnout (Sobel $=-3.20, p<0.01$ and Sobel $=-6.49, p<0.001$, partial mediations). For the 3 dimensions of the JCQ it totally mediated the prediction for decisional latitude (Sobel $=5.06, p<0.001$ ) and mediated partially the prediction for social support (Sobel $=8.14, p<0.001$ ), but failed to predict significantly psychological demand (Sobel $=-1.75, p<0.10$ ns.). In other words, the feeling of belonging plays a mediating role, this time in a more nuanced fashion but, nevertheless, present with most of the variables studied (Table 5).

\subsubsection{Mediating role of the feeling of belonging between the} perception of the quality of relationships with members of management and the different dimensions of the MBI and the JCQ

This third analysis concerned the prediction of measures of quality of life by the quality of connections with the management. This time the mediating role of the feeling of belonging was only partial for emotional burnout, and depersonalisation (Sobel $=-5.71, p<0.001$; Sobel $=-2.64, p<0.01$ ). On the other hand, there was a total mediation with personal fulfilment (Sobel $=5.88$, $p<0.001$ ). With regard to the JCQ, decisional latitude and social support were partially mediated (Sobel $=4.65, p<0.001$; Sobel $=6.73$, $p<0.001)$. But there was no mediation for psychological demand (Sobel $=-1.18, \mathrm{~ns}$.): although lower quality relationships with the
Table 6

Summary of Sobel tests evaluating the feeling of belonging as a mediator between the perceived quality of relationships with members of the management and the dimensions of the $\mathrm{MBI}$ and the JCQ. ${ }^{\mathrm{a}}$.

\begin{tabular}{lllll}
\hline Predicted variables of quality of life & B & ETB & Z & Mediation \\
\hline MBI - Emotional burnout & -2.15 & 0.34 & $-5.71^{* *}$ & Partial \\
MBI - Depersonalisation & -0.51 & 0.19 & $-2.64^{*}$ & Partial \\
MBI - Personal fulfilment & 1.64 & 0.25 & $5.88^{* *}$ & Total \\
JCQ - Psychological demand & -0.17 & 0.14 & -1.18 & ns \\
JCQ - Decisional latitude & 1.63 & 0.33 & $4.65^{* *}$ & Partial \\
JCQ - Social support & 0.83 & 0.11 & $6.73^{* *}$ & Partial \\
\hline
\end{tabular}

a Coefficient of 0.39 and standard deviation 0.03 .

${ }^{*} p<0.01$.

** $p<0.001$.

Table 7

Summary of Sobel tests evaluating the feeling of belonging as a mediator between the perceived quality of relationships with the administrative staff and the dimensions of the MBI and the JCQ. ${ }^{\text {a }}$

\begin{tabular}{lllll}
\hline Predicted variables of quality of life & B & ETB & Z & Mediation \\
\hline MBI - Emotional burnout & -2.62 & 0.32 & $-5.62^{* * *}$ & Partial \\
MBI - Depersonalisation & -0.69 & 0.17 & $-3.62^{* *}$ & Partial \\
MBI - Personal fulfilment & 1.61 & 0.23 & $5.22^{* * *}$ & Partial \\
JCQ - Psychological demand & -0.17 & 0.14 & $-2.40^{*}$ & Partial \\
JCQ - Decisional latitude & 1.95 & 0.31 & $4.90^{* * *}$ & Total \\
JCQ - Social support & 1.21 & 0.11 & $6.39^{* * *}$ & Partial \\
\hline
\end{tabular}

a Coefficient of 0.28 and standard deviation 0.04 .

${ }^{*} p<0.05$.

** $p<0.01$.

$p<0.001$.

management predicted a high psychological demand, the feeling of belonging to the work group did not seem to be able to intervene in this relationship, although it was correlated with the perceived quality of this relationship with the management (Table 6).

\subsubsection{Mediating role of the feeling of belonging between the} quality of relationships with the administrative staff and the different dimensions of the MBI and the JCQ

The last relationship studied was the prediction of quality of life by the perceived quality of relationships with the administrative staff. The results in this area most often indicated existing mediations, albeit partial (Sobel $=-5.62, p<0.001$; Sobel $=-3.62$, $p<0.01$; Sobel $=5.22, p<0.001$; Sobel $=-2.40, p<0.05$; Sobel $=6.39$, $p<0.001$ ) with the exception of the prediction of decisional latitude, for which mediation was total (Sobel $=4.90, p<0.001$ ) (Table 7).

\subsubsection{Mediating role of the feeling of belonging between the} mean perceived relationship and the different dimensions of the $M B I$ and the JCQ

In order to go further, we tested here the hypothesis according to which the impact of the quality of relationships in general (estimated via the mean quality of the 4 relationships) on the quality of life at work, could be mediated by the feeling of belonging. Partial mediations were observed for the dimensions of the MBI significantly for emotional burnout and self-fulfilment (Sobel $=-4.54$, $p<0.001$ and Sobel $=5.00, p<0.001$ ) with a tendency for depersonalisation (Sobel $=-1.91$, two-tailed $p<0.06, t$ ). The results were more variable in respect of the 3 dimensions of the JCQ, with a total mediation for the impact of relationships on decisional latitude (Sobel $=4.54, p<0.001$ ), partial mediation for the prediction of social support (Sobel $=6.59, p<0.001$ ), and an absence of mediation for psychological demand (Sobel $=-0.12$, ns.) (Table 8).

On reading the results, it seems that, overall, when relationships are perceived as relaxed, the feeling of belonging is experienced as strong and in so doing the latter contributes to the quality of life at work. It may explain, when relationships are good, a decisional 
Table 8

Summary of Sobel tests evaluating the feeling of belonging as a mediator between the mean of the four relationships studied and the dimensions of the MBI and the Karasek questionnaire. ${ }^{\text {a }}$

\begin{tabular}{lllll}
\hline Variables of quality of life predicted & B & ETB & Z & Mediation \\
\hline MBI - Emotional burnout & -1.73 & 0.37 & $-4.54^{* * *}$ & Partial \\
MBI - Depersonalisation & -0.39 & 0.20 & -1.91 & t \\
MBI - Personal fulfilment & 1.42 & 0.27 & $5.00^{* * *}$ & Partial \\
JCQ - Psychological demand & -0.02 & 0.16 & -0.12 & ns \\
JCQ - Decisional latitude & 1.69 & 0.36 & $4.54^{* * *}$ & Total \\
JCQ - Social support & 0.86 & 0.12 & $6.59^{* * *}$ & Partial \\
\hline
\end{tabular}

${ }^{*} p<0.05$ and ${ }^{* *} p<0.01$.

a Coefficient of 0.67 and standard deviation 0.04 .

*** $p<0.001$.

latitude perceived as greater (illustrated by Fig. 2), and lead to perceiving oneself as more socially supported and to feeling lower emotional burnout and better self-fulfilment at work.

As our approach was observational (the quality of relationships not being the product of an experiment here), we can only reasonably estimate that the feeling of belonging accounts for the connection between these measures and intervenes as a promising latent variable. Finally, this general result is not necessarily invariable. This is particularly the case, when a lower quality of relationships with the management predicts a psychological demand perceived as high, without the feeling of belonging intervening at this level.

\section{Discussion}

The aim of this study was to highlight the connections existing between the feeling of belonging and the different variables used in the measure of the quality of life at work (six dimensions taken from the models of Karasek and Maslach). Overall our hypothesis was validated; in fact, all variables could be predicted by the feeling of belonging. In addition, this psychological construct seems to be specific, and to predict most directly perceived decisional latitude and feeling of self-fulfilment at work. It also intervenes specifically, but less primarily, in the prediction of emotional burnout. The feeling of belonging is also a specific construct directly linked to the quality of relationships with the care team and, less primarily, with the management and the administrative staff.

A first interesting element of this study is the fact that the quality of relationships is a predictor of well-being at work. This result extends the observations made amongst care staff and teachers who see in the quality of relationships a factor which can improve well-being at work (Roland-Lévy et al., 2014). Our observations confirm the actual existence of a connection between the quality of relationships, work content perceived more positively and a lower burnout level. A good quality of human relationships in the organisation therefore appears to be a preventive or remedial factor for problematic situations and suffering at work.
In this regard, it seems to us that it would be advantageous to develop the group dimension of the activity (Caroly \& Barcellini, 2013), in order to encourage relationships within teams, recourse to the work group and the feeling of belonging. This development of "collective activity at work" could be achieved through (a) the development of group rather than exclusively individual performance and pay, (b) the introduction of time for reflection on the resolution of problems linked to the activity, (c) on quality of work, (d) on work processes and the resolution of constraints linked to work as it is prescribed, (e) the identification of everyone's skills and their synchronisation and (f) the debating of the meaning of work. As noted by Caroly and Barcellini (2013), collective activity at work develops the feeling of being part of a group and is beneficial both for the performance of teams and psychological well-being at work. We could therefore expect such actions promoting recourse to mutual assistance to lead to decisional latitude and self-fulfilment, and, in short, to improve the well-being at work, both collectively and individually (Bonnel \& Py, 2015).

This proposal appears to us to be especially likely with regard to the mediating role of belonging. We should remember that we also started with the premise that a good quality of relationships could induce a strong feeling of belonging and thus explain the impact of the quality of relationships on the six dimensions of quality of life used. The mediation analyses yielded results consistent with this premise, especially for relationships within the care team. They confirm the centrality of the feeling of belonging to the group in the question of well-being at work. These results are consistent with the first observations of Skaalvik and Skaalvik (2011a, 2011b) on the protective role of the feeling of belonging in the shift from emotional burnout to the intention to resign. The mediations observed here are mostly total with regard to decisional latitude and selffulfilment at work. One might think that the feeling of belonging to a work group would play a subjective role, at least with regard to some of the dimensions of well-being experienced. Therefore, when relationships appear to be good, and the feeling of belonging high, the employee is likely to feel that they have decisional latitude in organising their work and can find fulfilment in it. Trust in the work group and the quality of relationships with others is likely to lead the employee to perceive themselves as freer, with a latitude to manage their activity in a flexible rather than a prescribed way, even when the workload is constrained by care profitability targets which management are monitoring.

Regarding relationships with the management, a mediation of the feeling of belonging was not observed, specifically for the psychological demands of work. We should remember that the role of Healthcare Executives is not only to monitor the continuity of care provided, but also and above all, from a management point of view, to reduce the financial and temporal costs of teams' activities. As the role of management is therefore to monitor the workload of subordinates, it is not very surprising that relationships with the latter are worse when workload and psychological demands are excessive, and this independently of the feeling of

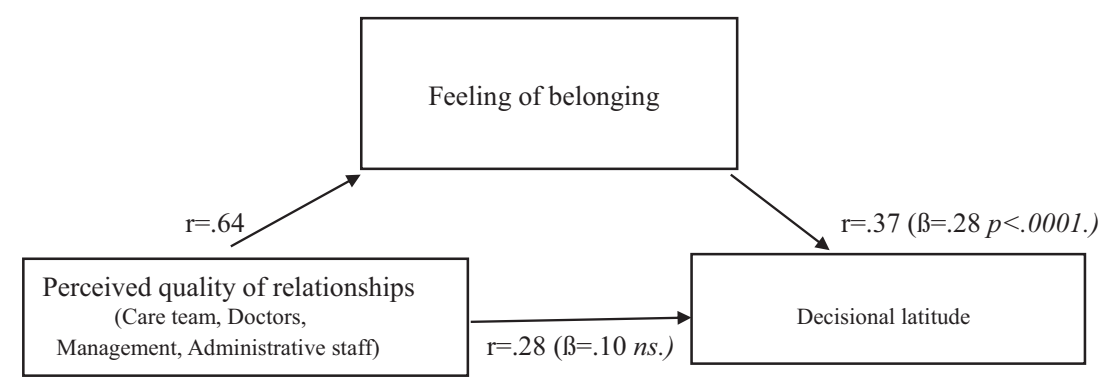

Fig. 2. Mediating role of the feeling of belonging in the prediction of decisional latitude by the perceived quality of relationships within the organisation. 
belonging to the group and the organisation. Nevertheless, the fact that relationships with management are strongly linked to the social support experienced by employees underlines the necessity for "proximity" management, giving employees more social support (Halbesleben, 2006) and promoting a feeling of self-fulfilment at work.

The results of our study generally underline the importance of human relationships in the quality of life experienced at work. It seems essential to work to improve the quality of these relationships in order to develop the feeling of belonging and contribute to a good quality of life. A longitudinal and quasi-experimental approach should therefore be devised, to increase the quality of human relationships at work and positive inter-dependencies between the members of work teams. This approach could target, in a participatory way, the themes proposed by a large majority of the care staff, such as support for teams and communication with them, respect for employees and listening to them (Roland-Lévy et al., 2014). Supporting management in the implementation of social support for teams can therefore be envisaged. In this regard, Ruiller and Van Der Heijden (2016) underline the importance of receptive support characterised by the attention and availability of managers to their team members, but also the importance of support for initiatives related to the autonomy granted by the manager to their subordinates. It finally underlines the importance of a support for authority which meets the expectations of the manager in terms of respect for group rules and for the efforts expended by everyone for the group. This support could be based on measures aiming to develop collective work activities, thus leading to more cooperative and collaborative work.

Actions aiming to increase teams' feeling of belonging and cohesion via "collective work activities" supported by the management, seem to us to be avenues of interest, insofar as the feeling of belonging is a fairly direct predictor of the dimensions of quality of life of the care staff questioned here. Developing a feeling of belonging and identification with the team can then be one of the possible means for increasing well-being at work, by offering employees a larger social, emotional and operational network. In this regard, the role of the management could be to offer care staff opportunities to develop positive interdependent relationships in the performance of their collective work activities, times for discussion in order to review ways of carrying out these activities and promote group performance targets and, thus, a general feeling of social support and well-being at work.

\section{Disclosure of interest}

The authors declare that they have no competing interest.

\section{Appendix A. Supplementary data}

Supplementary data associated with this article can be found, in the online version, at https://doi.org/10.1016/j.erap.2017.10.003.

\section{References}

Ashforth, B. E., Harrison, S. H., \& Corley, K. G. (2008). Identification in organizations: An examination of four fundamental questions. Journal of Management, 34, 325-374 (https://doi.org/10.1177/0149206308316059)

Bakker, A. B., Demerouti, E., \& Euwema, M. C. (2005). Job resources buffer the impact of job demands on burnout. Journal of Occupational Health Psychology, 10,170-180 (https://doi.org/10.1037/1076-8998.10.2.170)

Bonnel, F., \& Py, J. (2014). Contribution to professional development with a sponsorship skill project: Enhancing organizational citizenship behaviors and wellbeing at work. Presented at the 28th international congress of applied psychology, Paris.

Bradley, H. B. (1969). Community-based treatment for young adult offenders. Crime E' Delinquency, 15, 359-370 (https://doi.org/10.1177/001112876901500307)
Buton, F., Fontenay, P., \& Heuzé, J. (2006). La cohésion des groupes sportifs : Évolutions conceptuelles, mesures et relations avec la performance [The cohesion of sports groups: Conceptual changes, measures and relations with performance]. Science et Motricité, 59, 10-45 (https://doi.org/10.3917/sm.059.0009)

Caroly, S., \& Barcellini, F. (2013). Le développement de l'activité collective [The development of collective activity]. In P. Falzon (Ed.), Ergonomie constructive (pp. 33-46). Paris, France: PUF (https://halshs.archives-ouvertes.fr/halshs-00860638)

Cerclé, A., Gadea, C., Hartmann, A., \& Lourel, M. (2008). Typological and factor analysis of the perceived stress measure by using the PSS scale. European Review of Applied Psychology, 58, 227-239 (https://doi.org/10.1016/j.erap.2008.09.006)

Chatot-Henry, D., Chatot-Henry, C., \& Courcier, D. (2014). La promotion de la santé : Un concept pertinent comme outil de management et de dynamique organisationnelle dans la restructuration d'un hôpital gériatrique [Health promotion: A relevant concept as a tool for management and organizational dynamics in the restructuring of a geriatric hospital]. Santé Publique, 26, 453-467 (http://www.cairn.info/revue-sante-publique-2014-4-page-453.htm)

Chedotel, F. (2004). Avoir le sentiment de faire partie d'une équipe : De l'identification à la coopération [To feel part of a team: From identification to cooperation]. Management, 7, 161-193 (https://doi.org/10.3917/mana.073.0161)

Chevrier, S. (2012). Peut-on faire virtuellement équipe ? Le cas des équipes internationales de projet [Can we do virtually team? The case of international project teams]. Nouvelle Revue de Psychosociologie, 14, 35-50 (https://doi.org/10.3917/nrp.014.0035)

Clot, Y.(2008). Occupational health: Models, measures and actions. European Review of Applied Psychology, 58, 297-299 (https://doi.org/10.1016/j.erap.2008.09.012)

Conjard, P., \& Journoud, S. (2013). Ouvrir des espaces de discussion pour manager le travail [Open discussion spaces to manage the work]. Management $\mathcal{E}$ Avenir, 63, 81-97 (https://doi.org/10.3917/mav.063.0081)

Cooper, D., \& Thatcher, C. (2010). Identification in organizations: The role of selfconceptorientations and identification motives. Academy of Management Review, 35, 516-538 (https://doi.org/10.1177/1059601112473815)

Dameron, S. (2004). Opportunisme ou besoin d'appartenance ? La dualité coopérative dans le cas d'équipe de projet [Opportunity or need of belonging? Cooperative duality in the case of a project team]. Management, 3, 137-160 (https://doi.org/10.3917/mana.073.0137)

Freudenberger, H. J. (1974). Staff burn-out. Journal of social issues, 30, 159-165 (https://doi.org/10.1111/j.1540-4560.1974.tb00706.x)

Gilibert, D., \& Daloz, L. (2008). Disorders associated with burnout and causal attributions of stress among health care professionals in psychiatry. European Review of Applied Psychology, 58, 263-274 (https://doi.org/10.1016/j.erap.2008.09.009)

Gueudar-Delahaye, A. (2012). Faire équipe entre ciel et terre : Le cas des navigants aériens [Teaming up between sky and earth: The case of aircrew]. Nouvelle Revue de Psychosociologie, 14, 51-66 (https://doi.org/10.3917/nrp.014.0051)

Guilbert, L., Carrein, C., Guenole, N., Priolo, D (in press). Relationship between perceived organizational support, proactive personality and perceived employability in workers over 50. Journal of Employement Counseling. JOEC-Jul-15-027.R1 https://www.researchgate.net/publication/294860641_.

Halbesleben, J. (2006). Sources of social support and burn out: A meta-analytic test oh the conservation of ressources model. Journal of Applied Psychology, 91, 1134-1145 (https://doi.org/10.1037/0021-9010.91.5.1134)

Karaseck, R. A., Jr. (1979). Job demands, job decision latitude, and mental strain: Implications for job redesign. Administrative Science Quarterly, 285-308 (https://doi.org/10.2307/2392498)

Lachmann, H., Larose, C., \& Penicaud, M. (2010). Bien-être et efficacité au travail - 10 propositions pour améliorer la santé psychologique au travail. Rapport fait à la demande du Premier ministre français [Workplace well-being and effectiveness - 10 proposals to improve workplace psychological health. Report made at the request of the French Prime].

Lamrani, J. (2014). Le travail de décider [The work of deciding]. Connexions, 101, 61-78 (https://doi.org/10.3917/cnx.101.0061)

Laugaa, D., Rascle, N., \& Bruchon-Schweitzer, M. (2008). Stress and burnout among French elementary school teachers: A transactional approach. European Review of Applied Psychology, 58, 241-251 (https://doi.org/10.1016/j.erap.2008.09.007)

Levett-Jones, T., \& Lathlean, J. (2008). Belongingness: A prerequisite for nursing students' clinical learning. Nurse Education in Practice, 8, 103-111 (https://doi.org/10.1016/j.nepr.2007.04.003)

Marc, J., Grosjean, V., \& Marsella, M. (2011). Dynamique cognitive et risques psychosociaux : Isolement et sentiment d'isolement au travail [Cognitive dynamics and psychosocial risks: Isolation and isolation at work]. Le Travail Humain, 74 107-130 (https://doi.org/10.3917/th.742.0107)

Maslach, C., \& Jackson, S. E.(1981). The measurement of experienced burnout. Journal of Organizational Behavior, 2, 99-113 (https://doi.org/10.1002/job.4030020205)

Pansu, P., Tarquinio, C., \& Gilibert, D. (2005). Internal attributions in an intergroup business setting. Le travail humain, 68, 55-72 (https://doi.org/10.3917/th.681.0055)

Porter, L. W., Steers, R. M., Mowday, R. T., \& Boulian, V. (1974). Organizational commitment, job satisfaction, and turnover among psychiatric technicians. Journal of Applied Psychology, 59, 603 (https://doi.org/10.1037/h0037335)

Roland-Lévy, C., Lemoine, J., \& Jeoffrion, C. (2014). Health and well-being at work: The hospital context. European Review of Applied Psychology, 64, 53-62 (https://doi.org/10.1016/j.erap.2014.01.002)

Ruiller, C., \& Van Der Heijden, B. I. (2016). Socio-emotional support in French hospitals: Effects on French nurses' and nurse aides' affective commitment. Applied Nursing Research, 29, 229-236 (https://doi.org/10.1016/j.apnr.2015.06.006) 
Skaalvik, E. M., \& Skaalvik, S. (2011a). Teacher job satisfaction and motivation to leave the teaching profession: Relations with school context, feeling of belonging, and emotional exhaustion. Teaching and Teacher Education, 27, 1029-1038 (http://doi.org/10.1016/j.tate.2011.04.001)

Skaalvik, E. M., \& Skaalvik, S. (2011b). Teachers' feeling of belonging, exhaustion, and job satisfaction: the role of school goal structure and value consonance. Anxiety, Stress \& Coping, 24, 369-385 (https://doi.org/10.1080/10615806.2010.544300)

Vandenberghe, C., Stordeur, S., \& d'Hoore, W. (2009). Une analyse des effets de la latitude de décision, de l'épuisement émotionnel et de la satisfac- tion au travail sur l'absentéisme au sein des unités de soins infirmiers [An analysis of the effects of decision latitude, emotional exhaustion and job satisfaction on absenteeism in nursing units]. Le Travail Humain, 72, 209-228 (https://doi.org/10.3917/th.723.0209)

Wiesenfeld, E. (1996). The concept of "we": A community social psychology myth? Journal of Community Psychology, 24, 337-346 (https://doi.org/10.1002/(SICI)1520-6629(199610)24:4<337::AID-

JCOP4>3.0.CO;2-R). 